\title{
Paternal phylogeographic structure of the brown bear (Ursus arctos) in northeastern Asia and the effect of male-mediated gene flow to insular populations
}

Daisuke Hirata', Tsutomu Mano², Alexei V. Abramov³, Gennady F. Baryshnikov³, Pavel A. Kosintsev4, Koichi Murata ${ }^{5}$ and Ryuichi Masuda ${ }^{1 *}$ (D)

\begin{abstract}
Background: Sex-biased dispersal is widespread among mammals, including the brown bear (Ursus arctos). Previous phylogeographic studies of the brown bear based on maternally inherited mitochondrial DNA have shown intraspecific genetic structuring around the northern hemisphere. The brown bears on Hokkaido Island, northern Japan, comprise three distinct maternal lineages that presumably immigrated to the island from the continent in three different periods. Here, we investigate the paternal genetic structure across northeastern Asia and assess the connectivity among and within intraspecific populations in terms of male-mediated gene flow.
\end{abstract}

Results: We analyzed paternally inherited Y-chromosomal DNA sequence data and Y-linked microsatellite data of 124 brown bears from Hokkaido, the southern Kuril Islands (Kunashiri and Etorofu), Sakhalin, and continental Eurasia (Kamchatka Peninsula, Ural Mountains, European Russia, and Tibet). The Hokkaido brown bear population is paternally differentiated from, and lacked recent genetic connectivity with, the continental Eurasian and North American populations. We detected weak spatial genetic structuring of the paternal lineages on Hokkaido, which may have arisen through male-mediated gene flow among natal populations. In addition, our results suggest that the different dispersal patterns between male and female brown bears, combined with the founder effect and subsequent genetic drift, contributed to the makeup of the Etorofu Island population, in which the maternal and paternal lineages show different origins.

Conclusions: Brown bears on Hokkaido and the adjacent southern Kuril Islands experienced different maternal and paternal evolutionary histories. Our results indicate that sex-biased dispersal has played a significant role in the evolutionary history of the brown bear in continental populations and in peripheral insular populations, such as on Hokkaido, the southern Kuril Islands, and Sakhalin.

Keywords: Brown bear, Hokkaido, Phylogeography, Sex-biased dispersal, Ursus arctos, Y-chromosomal DNA

\footnotetext{
* Correspondence: masudary@sci.hokudai.ac.jp

'Department of Biological Sciences, Faculty of Science, Hokkaido University,

Sapporo 060-0810, Japan

Full list of author information is available at the end of the article
} 


\section{Background}

Molecular studies based on both biparentally and uniparentally inherited, sex-specific genetic markers have shown empirically that sex-biased dispersal is widespread among mammals, but varies widely in direction and intensity [1-3]. Most mammals show male-biased dispersal (males disperse from their natal area) and female philopatry (females stay in the natal area) [4-6]. Sexually incongruent patterns of genetic differentiation resulting from sex-biased migration are known from diverse taxonomic groups of large mammals, including humans (Homo sapiens) [7, 8], bonobos (Pan paniscus) [9], chimpanzees (Pan troglodytes) [10], orangutans (Pongo spp.) [11, 12], hamadryas baboon (Papio hamadryas hamadryas) [13], canids (Canis lupus) [14, 15], and domesticated animals, such as sheep (Ovis spp.) and horses (Equus caballus) [16, 17]. The brown bear (Ursus arctos), which is widely distributed throughout the Holarctic region, shows strongly male-biased dispersal [18-21], and sex-biased dispersal has significantly influenced the molecular evolutionary history of ursids in general [22].

Some previous phylogeographic studies of the brown bear based on maternally inherited mitochondrial DNA (mtDNA) showed extensive intraspecific geographical genetic structuring in maternal lineages [23-27]. The brown bear population on Hokkaido Island, northern Japan, an insular population peripheral to the Eurasian Continent, is composed of three distinct allopatrically distributed mtDNA lineages $[25,28]$. These three maternal lineages apparently diverged on the Eurasian Continent prior to migration onto Hokkaido via land bridges in three different glacial periods, with a southern Hokkaido lineage having colonized first, followed by eastern and then central Hokkaido lineages.

While Hokkaido Island $\left(77,984 \mathrm{~km}^{2}\right)$ is much smaller than the adjacent continent, the maternal genetic diversity is higher there than in northern continental Eurasia, where the brown bear predominantly shows a single mtDNA lineage [26, 29-31]. The high level of diversity on Hokkaido is a consequence of the multiple lineages that originated allopatrically and remained allopatric on Hokkaido through female philopatry.

In addition to using maternally inherited mtDNA, the influence of sex-biased gene flow can be measured by using sex-linked markers in the male-specific, non-recombining region of the Y-chromosome [32-36]. In contrast to the genetic structuring evident in brown bear mtDNA, Y-chromosomal DNA shows low intraspecific variation, with no clear phylogeographic structure throughout the Holarctic region [34]. Extensive male-biased dispersal is thought to have resulted in gene flow across large geographical distances and between Asia and the North America, tending to homogenize genetic variation.

The role of male-mediated gene flow in the evolutionary history of brown bears seems to depend on the time interval and distributional area under consideration, and the presence or absence of previous occupant populations. Male-mediated gene flow could have connected bear populations of the Alaskan $\mathrm{ABC}$ islands with those of the North American mainland, and played a substantial role in maintaining high genetic variation in insular populations [34]. On the other hand, assessments of male gene flow during recovery of the brown bear from near extinction in Scandinavia suggest that male gene flow probably had little or no impact on the demographic recovery [36]. Lack of wide-ranging male gene flow during the short time of the recovery process resulted in low haplotype diversity and a low degree of haplotype admixture for Y-chromosomal DNA in post-bottleneck populations, suggesting that both males and females contributed to large-scale genetic connectivity in this case.

It has been hypothesized that both male and female brown bears together colonized Hokkaido from the Eurasian Continent multiple times during those periods. There may have been multiple patrilineal lineages of the brown bear in Hokkaido in the past, as with matrilineal lineages, without considering the male-biased dispersal of the brown bear. If this colonization process had occurred and male-mediated gene flow had not played a role for homogenizing patrilineal genetic variation, patrilineal phylogeographic structure in Hokkaido comprised of multiple patrilineal lineages would be expected.

To further understand the comprehensive evolutionary history of the brown bear in northeastern Asia, it is necessary to consider sex-biased migration and the role males played in forming the populations on Hokkaido and adjacent islands in terms of their contribution to genetic variation. Here we report polymorphism in Y-chromosomal DNA sequences and Y-linked microsatellites in the brown bear populations in Hokkaido, the southern Kuril Islands (Kunashiri and Etorofu), Sakhalin, and continental Eurasia (Kamchatka Peninsula, Ural Mountains, European Russia, and Tibet). We discuss the effects of sex-biased migration on the evolutionary history of the insular and continental populations, and differences in the male genetic contribution to the population composition. Finally, we assess the strength of male-mediated gene flow among geographically adjacent insular populations in northeastern Asia.

\section{Methods}

\section{Samples and DNA extraction}

Muscle or liver samples from 55 male brown bears collected on Hokkaido Island were obtained from the Environmental and Geological Research Department, Hokkaido Research Organization (Fig. 1). Tissue samples from males were also obtained from the following regions and sources: 10 samples from Etorofu (Iturup) Island, one from Kunashiri (Kunashir) Island, one from southern Sakhalin, and one from Novgorod (Zoological Institute, 


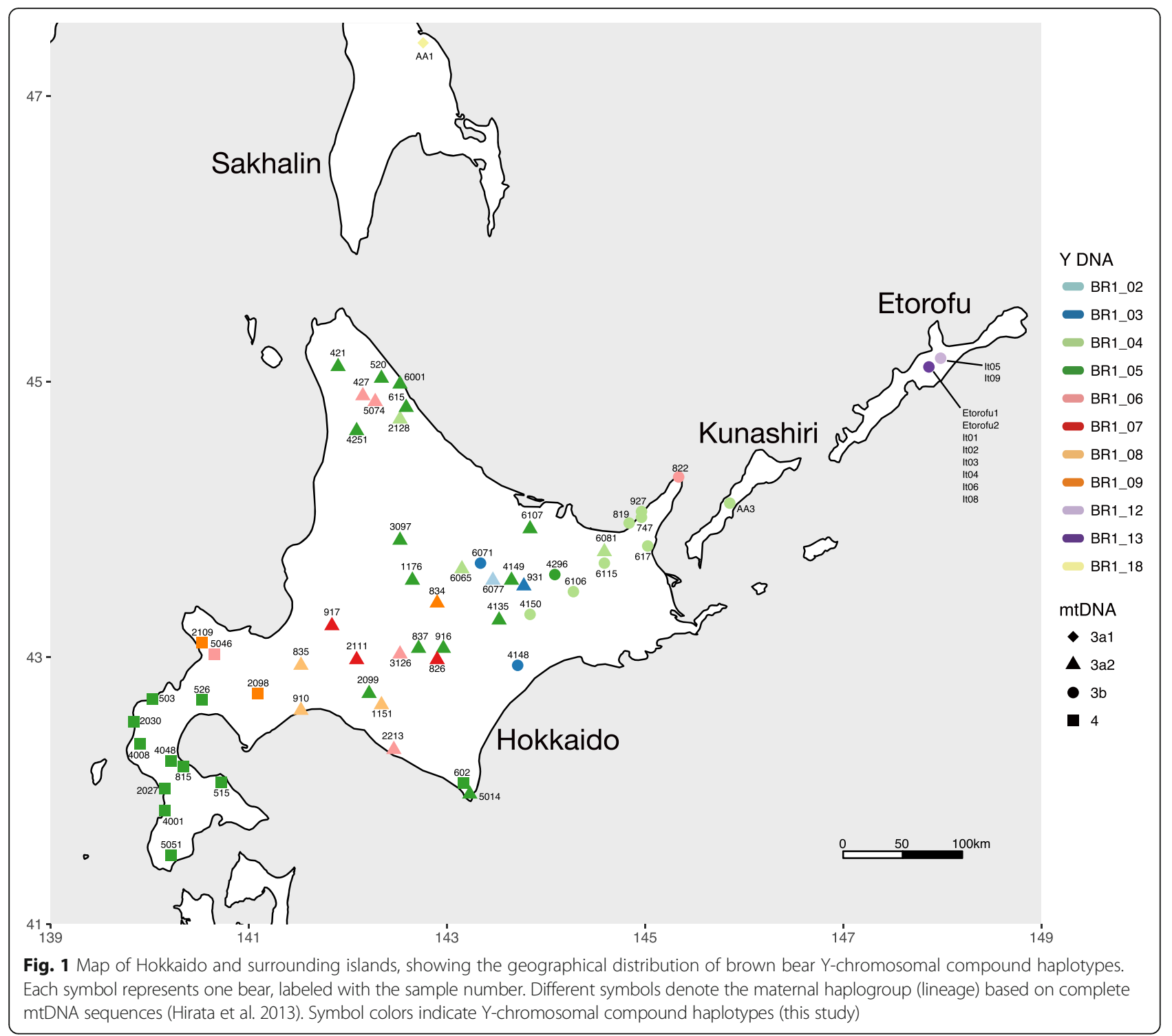

Russian Academy of Sciences, St. Petersburg); 53 from the Ural Mountains, and two from the Kamchatka Peninsula (Museum of the Institute of Plant and Animal Ecology, Russian Academy of Sciences, Ekaterinburg); and hairs of one male individual from Tibet (Kobe Municipal Oji Zoo, Japan) (Fig. 1, Additional file 1: Figures S4 and S5). The gender of samples was determined using the method of Bidon et al. [37]. Total genomic DNA was extracted with a DNeasy Tissue \& Blood Kit (QIAGEN) or QIAamp DNA Micro Kit (QIAGEN), following the manufacturer's protocols. PCR amplifications were performed in $5 \mu \mathrm{l}$ reaction volumes, each containing $2.5 \mu \mathrm{l}$ of $2 \times$ Multiplex PCR Master Mix (QIAGEN), $0.5 \mu \mathrm{l}$ of primer mixture, $0.25 \mu \mathrm{l}$ of bovine serum albumin (BSA; $0.4 \mu \mathrm{g} / \mu \mathrm{l}$ ), $0.75 \mu \mathrm{l}$ of distilled water, and $1.0 \mu \mathrm{l}$ of DNA extract.

\section{PCR amplification, sequencing, and microsatellite genotyping}

Female brown bear samples were included in each round of PCR amplification as a control to confirm male specificity. No amplification was observed from female samples in any round of amplification.

The same sequencing primer sets and touchdown thermal cycling conditions as described in Bidon et al. [34] were used to amplify seven Y-linked sequence fragments (318.2C, 318.3C, 318.7C, 318.10B, 318.11C, 579.1B, and 579.3C). Touchdown PCR amplifications were conducted in $10 \mu \mathrm{l}$ reaction volumes each containing $2.0 \mu \mathrm{l}$ of $5 \times$ PrimeSTAR GXL DNA Buffer (Takara), $0.8 \mu \mathrm{l}$ of dNTP mixture (2.5 mM each dNTP; Takara), $0.2 \mu$ l of PrimeSTAR GXL DNA Polymerase (1.25 U/ $\mu \mathrm{l}$, Takara), $0.1 \mu \mathrm{l}$ each of forward and reverse primers $(25 \mathrm{pmol} / \mu \mathrm{l})$, 
$0.2 \mu \mathrm{l}$ of BSA $(0.4 \mu \mathrm{g} / \mu \mathrm{l}), 5.2-6.2 \mu \mathrm{l}$ of distilled water, and 1.0-2.0 $\mu \mathrm{l}$ of DNA extract. Touchdown thermal cycling conditions were $3 \mathrm{~min}$ at $95{ }^{\circ} \mathrm{C} ; 10$ cycles of $30 \mathrm{~s}$ at $94{ }^{\circ} \mathrm{C}, 25 \mathrm{~s}$ at $69{ }^{\circ} \mathrm{C}, 66{ }^{\circ} \mathrm{C}$ (decreasing by $0.5^{\circ} \mathrm{C}$ per cycle), or $68{ }^{\circ} \mathrm{C}$ (decreasing by $1{ }^{\circ} \mathrm{C}$ per cycle), and $75 \mathrm{~s}$ at $72{ }^{\circ} \mathrm{C}$; 25 cycles of $30 \mathrm{~s}$ at $94{ }^{\circ} \mathrm{C}, 25 \mathrm{~s}$ at $64{ }^{\circ} \mathrm{C}$, $61{ }^{\circ} \mathrm{C}$, or $58{ }^{\circ} \mathrm{C}$, and $75 \mathrm{~s}$ at $72{ }^{\circ} \mathrm{C}$; and a final extension for $10 \mathrm{~min}$ at $72{ }^{\circ} \mathrm{C}$. PCR products were purified with a QIAquick Purification Kit (QIAGEN), following the manufacturer's protocol. DNA cycle sequencing was performed with BigDye v3.1 Cycle Sequencing Kit (Applied Biosystems, $\mathrm{ABI}$ ), using the same primers as for PCR amplification. PCR for sequencing was performed in $10 \mu \mathrm{l}$ volumes each containing $1.75 \mu$ l of $5 \times$ BigDye Sequencing Buffer (ABI), $0.5 \mu \mathrm{l}$ of Ready Reaction Premix (ABI), $1.6 \mu \mathrm{l}$ of primer $(1 \mathrm{pmol} / \mu \mathrm{l}), 5.15 \mu \mathrm{l}$ of distilled water, and $1.0 \mu \mathrm{l}$ of DNA template. Twenty-five cycles of $10 \mathrm{~s}$ at $96^{\circ} \mathrm{C}, 5 \mathrm{~s}$ at $50{ }^{\circ} \mathrm{C}$, and $4 \mathrm{~min}$ at $60{ }^{\circ} \mathrm{C}$ were performed. Amplified DNA fragments were purified with isopropanol, and then formamide was added. Sequences were determined on an ABI 3730 DNA Analyzer, assembled and edited with phred/phrap/chromaseq [38-40], and aligned by using MUSCLE [41] in MEGA7 [42].

Nine Y-linked microsatellite alleles (Y318.1, Y318.2, Y318.4, Y318.6, Y318.9, Y369.1, Y369.4, Y69217.1, and Y15020.1) were determined by using two sets of multiplex PCRs, with the same primer sets as given in Bidon et al. [34]. Each multiplex PCR was performed in a $5 \mu \mathrm{l}$ reaction volume containing $2.5 \mu \mathrm{l}$ of $2 \times$ Multiplex PCR Master Mix (QIAGEN), $1.0 \mu \mathrm{l}$ of primer mixture, $0.25 \mu \mathrm{l}$ of BSA $(0.4 \mu \mathrm{g} / \mu \mathrm{l}), 0.25 \mu \mathrm{l}$ of distilled water, and $1.0 \mu \mathrm{l}$ of DNA extract. Touchdown thermal cycling conditions were $3 \mathrm{~min}$ at $95{ }^{\circ} \mathrm{C} ; 20$ cycles of $30 \mathrm{~s}$ at $94{ }^{\circ} \mathrm{C}, 25 \mathrm{~s}$ at $68{ }^{\circ} \mathrm{C}$ (decreasing by $0.5^{\circ} \mathrm{C}$ per cycle), and $75 \mathrm{~s}$ at $72{ }^{\circ} \mathrm{C}$; 15 cycles of $30 \mathrm{~s}$ at $94{ }^{\circ} \mathrm{C}, 25 \mathrm{~s}$ at $58^{\circ} \mathrm{C}$, and $75 \mathrm{~s}$ at $72{ }^{\circ} \mathrm{C}$; and a final extension for $10 \mathrm{~min}$ at $72{ }^{\circ} \mathrm{C}$. Y-linked microsatellites were determined with an ABI 3730 DNA Analyzer and the GeneScan 600 LIZ Size Standard (ABI). Microsatellite allele sizes were determined by using GeneMapper v4.1 (ABI). Nine Y-chromosome microsatellites (Y318.1, Y318.2, Y318.4, Y318.6, Y318.9, Y369.1, Y369.4, Y69217.1, and Y15020.1) were genotyped. Three of the microsatellites (Y369.4, Y69217.1, and Y15020.1) were excluded as some individuals had pseudoheterozygous genotypes, leaving six of the nine markers (Y318.1, Y318.2, Y318.4, Y318.6, Y318.9, and Y369.1); allele sizes are shown in Additional file 2: Table S1 for subsequent analysis.

\section{Data analyses}

\section{Summary statistics}

Data on brown bears, polar bears, and American black bears were added to our dataset from Bidon et al. [34]. In Bidon et al. [34], all 90 individuals were sequenced for $3078 \mathrm{bp}$ (3.1 kb) Y-chromosomal sequences, whereas only 44 individuals were sequenced for $5294 \mathrm{bp}(5.3 \mathrm{~kb})$ Y-chromosomal sequences. Thus we used $5.3 \mathrm{~kb}$ Ychromosomal sequences for the calculation of summary statistics and network reconstruction to maximize the number of sequence length for increasing the analysis resolution. For the remaining analyses, we used $3.1 \mathrm{~kb} \mathrm{Y}$ chromosomal sequences combined with Y-linked microsatellites to maximize the number of samples to cover more geographical ranges of the brown bears. Insertions and deletions (indels) were removed from the aligned sequences. The data set comprised $5287 \mathrm{bp}(5.3 \mathrm{~kb}$ data set) of Ychromosomal sequences from 168 brown bears. Summary statistics were calculated in DnaSP version 5.10.1 [43] and Arlequin ver. 3.5.2.2 [44], including the number of haplotypes $(\mathrm{H})$, frequency of the dominant haplotype $(\mathrm{fH})$, number of segregating sites (S), nucleotide diversity $(\pi)$, Watterson's $\theta_{W}$ (per site), Tajima's $D$, Fu and Li's $D$ and $F$, and Fu's $F_{S}$. Compound haplotypes were determined based on the combination of Y-linked SNPs in $3071 \mathrm{bp}(3.1 \mathrm{~kb}$ data set) of Y-chromosomal DNA and six Y-linked microsatellite alleles. The genetic diversity of Y-chromosomal compound haplotypes was determined based on 214 brown bears, with the number of haplotypes $(\mathrm{H})$, haplotype diversity $(\mathrm{HD} \pm \mathrm{SD})$, and mean number of pairwise differences $(\mathrm{MPD} \pm \mathrm{SD})$ calculated for each population. To assess the population size reductions, the modified Garza-Williamson (GW) index $(M=k / r+1$ where $k$ is the number of alleles and $r$ is the range in allele size) was calculated using Arlequin ver. 3.5.2.2 $[44,45]$. The GW index is small in populations that have experienced a recent bottleneck $(<0.68)$ and close to one in stationary populations [45].

\section{Haplotype network analysis}

A median-joining (MJ) network [46] of Y-chromosomal DNA compound haplotypes combined with the Y-linked SNPs in the $3.1 \mathrm{~kb}$ dataset and Y-linked microsatellites was reconstructed by using Network 5.0.0.0 (http:// www.fluxus-engineering.com). For network calculations, more quickly evolving microsatellite loci were weighted inversely to their variance in repeat length $(318.9=8$, $318.4=9,318.2=8,369.1=2,318.1=9$, and $318.6=1$ ), and SNP loci were weighted 10 times the greatest microsatellite weight (Y-linked SNPs $=90$ ) as per [15]. MJ networks were constructed for the $3.1 \mathrm{~kb}$ and $5.3 \mathrm{~kb}$ data sets by using POPART [47]. The nomenclature of haplotypes based on the $5.3 \mathrm{~kb}$ and $3.1 \mathrm{~kb}$ data sets corresponds to that of Bidon et al. [34]. Names of Y-chromosomal DNA compound haplotypes refer first to the $3.1 \mathrm{~kb}$ of Y-chromosomal DNA and then to the genotype from six microsatellite loci. The three sub-populations on Hokkaido Island (central, eastern, and southern) correspond to mtDNA clades $3 \mathrm{a} 2,3 \mathrm{~b}$, and 4 , respectively, from Matsuhashi et al. [28] and Hirata et al. [25]. 


\section{Population differentiation analysis}

Pairwise population differentiation values $\left(R_{\mathrm{ST}}\right)$ for $\mathrm{Y}$ chromosomal polymorphisms [48] were calculated with 1000 permutations by using Arlequin ver 3.5.2.2 [44]. Hierarchical analysis of molecular variance (AMOVA) was implemented in Arlequin ver 3.5.2.2. Geographical partitioning of Y-chromosomal polymorphisms was also tested by AMOVA, with partitions defined as the North American, Eurasian, Hokkaido, and Etorofu groups. Based on a preliminary AMOVA analysis, the Etorofu population was included in the Eurasian group for further analyses. The three populations in the Hokkaido group (central, eastern, and southern) were defined by mtDNA lineages as described above. Brown bear populations represented by only one individual (Tibet, Sakhalin, and Kunashiri) were excluded from the AMOVA analysis.

\section{TMRCA estimations by Bayesian analysis}

Times to the most recent common ancestors (TMRCAs) and the times of population splitting were estimated by using the Bayesian-based coalescent approach implemented in the software BATWING [49]. Time estimation for Ychromosomal lineages was implemented by including Y-linked SNPs treated as unique event polymorphism sites together with Y-linked microsatellite genotypes. Coalescence times were estimated for all brown bears, the Hokkaido and Etorofu brown bears, only Hokkaido brown bears, and only Etorofu brown bears. Single population model was specified for the TMRCA estimation and multiple population models were specified for the splitting time calculation. None of the neutrality tests was significantly different from the expectation under neutrality; thus, all of the analysis was implemented under the assumption of constant population size. Priors applied were a mean mutation rate of $6.9 \times 10^{-4}$ mutations per locus per generation determined for human Y-chromosomal microsatellite DNA, with the gamma distribution [50] according to the method of Wei et al. [8], and a mean effective population size of 10,000 , with the gamma distribution as per [15]. For each BATWING run, one million MCMC cycles were performed, with the first $10 \%$ of each run discarded as burn-in. All runs achieved effective sample sizes $>200$ for all parameters and the convergence of replicate MCMC runs were confirmed in Tracer v1.6.0 [51]. A generation time of 10 years was assumed for the brown bear [52] to allow conversion of generations into years. In the BATWING analyses, all brown bear individuals were included in the data set. Geographical population subdivisions were defined as Eurasia, North America, Hokkaido (treated as one population), and Etorofu. One individual from Kunashiri was included in the Hokkaido population and one individual from Sakhalin was included in the Eurasian population.

\section{Results}

Polymorphism and genetic diversity

No Y-chromosomal haplotypes were shared among brown bears, polar bears ( $U$. maritimus), and American black bears ( $U$. americanus), and each of these species was reciprocally monophyletic for both the $5.3 \mathrm{~kb}$ and $3.1 \mathrm{~kb}$ data sets (Additional file 1: Figures S1 and S2). In the $3.1 \mathrm{~kb}$ data set, including data from Bidon et al. [34], six haplotypes (BR1, BR2, BR3, BR4, BR5, and BR6) were found among 214 brown bears (Additional file 1: Figure S1). Novel haplotype BR6 was detected in four individuals from the Ural Mountains. Except for 11 individuals having minor haplotypes (BR2, BR3, BR4, BR5, and BR6), 207 individuals shared haplotype BR1, including all individuals from Hokkaido.

In the $5.3 \mathrm{~kb}$ data set, including data from Bidon et al. [34], nine haplotypes (BR1.1, BR1.2, BR1.4, BR1.5, BR2, BR3, BR5, BR6.1, and BR6.2) discriminated by nine segregating sites were found among 168 brown bears (Additional file 1: Figure S2). We identified four novel haplotypes (BR1.4, BR1.5, BR6.1, and BR6.2). The maximum number of nucleotide differences between haplotypes was five. BR1.4 was the most common haplotype, found in all brown bears from Hokkaido and in 98 individuals (58\% of total) from Hokkaido, Kunashiri, Etorofu, Sakhalin, Tibet, the Ural Mountains, Kamchatka, and European Russia. Three haplotypes (BR1.5, BR6.1, and BR6.2) were detected only in brown bears from Ural Mountains.

Nucleotide diversity $(\pi)$ and Watterson's $\theta_{W}$ per site for all brown bears were $(1.5 \pm 0.1) \times 10^{-4}$ and $(3.0 \pm 1.2) \times 10$

${ }^{-4}$, respectively. None of the four neutrality indices for the $5.3 \mathrm{~kb}$ data set was significantly different from the expectation under neutrality, nor did paternal brown bears experience a recent population expansion or contraction: Tajima's $D=-1.19(P>0.10), \mathrm{Fu}$ and Li's $D=-1.95$ $(P>0.05), \mathrm{Fu}$ and Li's $F=-2(P>0.05)$, Fu's $F s=-3.548$ $(P>0.05)$.

In all, 80 compound haplotypes, defined by SNPs in the $3.1 \mathrm{~kb}$ data set and the six microsatellites alleles, were found among 214 individuals (Additional file 2: Table S1), and 39 haplotypes were novel. Among the brown bear populations in western Asia, including the Ural Mountains, 32 haplotypes were detected, and both the haplotype diversity (HD $=0.96 \pm 0.01)$ and mean number of pairwise differences $(\mathrm{MPD}=3.59 \pm 1.85)$ were highest among the various regions (Table 1). A total of eight haplotypes were found among 55 individuals on Hokkaido. The MPD for Hokkaido was nearly one-third that of Western Asia, and was the lowest among all populations, except for Canada. Both genetic diversity indices for Hokkaido were lower $(\mathrm{HD}=0.73$ and $\mathrm{MPD}=1.23)$ than those for the North American and Eurasian continental populations, except for Canada. On Hokkaido, both HD 
Table 1 Paternal genetic diversity in various geographical populations of brown bears, based on 3.1-kb Y-chromosomal nucleotide sequences and six Y-linked microsatellite loci

\begin{tabular}{|c|c|c|c|c|c|}
\hline Population & $n$ & $\mathrm{H}$ & $\mathrm{HD} \pm \mathrm{SD}$ & $\mathrm{MPD} \pm \mathrm{SD}$ & $\mathrm{GW} \pm \mathrm{SD}$ \\
\hline All brown bears & 214 & 79 & $0.97 \pm 0.01$ & $4.08 \pm 2.04$ & - \\
\hline Northwest America $(\mathrm{NW}-\mathrm{A})^{\mathrm{a}}$ & 10 & 6 & $0.84 \pm 0.10$ & $2.31 \pm 1.38$ & $0.92 \pm 0.20$ \\
\hline$A B C$ Islands $(A B C)^{a}$ & 11 & 5 & $0.82 \pm 0.08$ & $1.82 \pm 1.13$ & $0.93 \pm 0.12$ \\
\hline Canada $(\mathrm{CAN})^{\mathrm{a}}$ & 8 & 2 & $0.25 \pm 0.18$ & $0.75 \pm 0.61$ & $0.89 \pm 0.19$ \\
\hline Central Europe $(C-E U)^{a}$ & 14 & 8 & $0.89 \pm 0.06$ & $2.68 \pm 1.52$ & $0.93 \pm 0.15$ \\
\hline Northern Europe $(\mathrm{N}-\mathrm{EU})^{\mathrm{a}}$ & 11 & 5 & $0.78 \pm 0.11$ & $2.62 \pm 1.51$ & $0.94 \pm 0.14$ \\
\hline Western Asia (W-AS) & 61 & 32 & $0.96 \pm 0.01$ & $3.59 \pm 1.85$ & $0.97 \pm 0.08$ \\
\hline East Asia (E-AS) & 31 & 14 & $0.86 \pm 0.05$ & $2.60 \pm 1.43$ & $0.94 \pm 0.16$ \\
\hline Sakhalin (SH) & 1 & 1 & 1.00 & 0.00 & - \\
\hline Tibet (TB) & 1 & 1 & 1.00 & 0.00 & - \\
\hline Etorofu (ET) & 10 & 2 & $0.36 \pm 0.16$ & $0.36 \pm 0.38$ & $1.00 \pm 0.00$ \\
\hline Kunashiri (KN) & 1 & 1 & 1.00 & 0.00 & - \\
\hline Hokkaido (HK) & 55 & 8 & $0.73 \pm 0.05$ & $1.23 \pm 0.79$ & $0.83 \pm 0.14$ \\
\hline Central Hokkaido (C-HK) & 30 & 8 & $0.76 \pm 0.07$ & $1.26 \pm 0.82$ & $0.83 \pm 0.14$ \\
\hline Eastern Hokkaido (E-HK) & 11 & 4 & $0.60 \pm 0.15$ & $0.85 \pm 0.65$ & $0.75 \pm 0.35$ \\
\hline Southern Hokkaido (S-HK) & 14 & 3 & $0.38 \pm 0.15$ & $0.41 \pm 0.40$ & $0.83 \pm 0.24$ \\
\hline
\end{tabular}

${ }^{\mathrm{a}}$ Citations from Bidon et al. [34]

$n$ sample size, $H$ number of haplotypes, HD haplotype diversity, MPD mean number of pairwise differences within population, GW modified Garza-Williamson index, SD standard deviation

and MPD were highest in central Hokkaido and lowest in southern Hokkaido (Table 1). All eight haplotypes detected on Hokkaido were represented in the central Hokkaido population. On Etorofu Island, only two haplotypes different by one microsatellite mutational step were found among 10 individuals, and the MPD was the lowest among all brown bear populations where multiple individuals were investigated. The GW index was calculated for each geographic population, and ranged from 0.75 (eastern Hokkaido) to 1.00 (Etorofu) (Table 1). The GW index of all geographic populations was greater than critical value of 0.68 for the indication of a recent population bottleneck and did not deviate from putatively stable populations [45].

\section{Haplotype networks}

Among all brown bear populations, only the Ychromosomal haplotypes from Hokkaido showed clear geographic clustering in the haplotype network (Fig. 2a and Additional file 1: Figure S3), sharing no haplotypes with continental Eurasian and North American populations; other populations showed no clear geographic structure. Y-chromosomal haplotypes were shared among the three Hokkaido populations, and their geographical distribution was not congruent with the population delineation by mtDNA (Figs 1 and $2 \mathrm{~b}$ ). Three male individuals (ID 602, 6071, and 6081 representing mtDNA clades 4, $3 \mathrm{~b}$, and $3 \mathrm{a} 2$, respectively) had outlying maternal haplotypes that were found within populations defined by other maternal haplotypes (mtDNA clades 3a2, 3a2, and 3b, respectively) (Fig. 1). These individuals had paternal haplotypes that in some cases were detected in presumed natal populations and in other cases dispersed across maternal population boundaries.

On Hokkaido Island, the paternal haplotype distribution did not show any allopatric separation, although a somewhat biased haplotype distribution was observed (Figs. 1 and 2b). All of the paternal haplotypes detected on Hokkaido were represented in the central population, which thus showed higher haplotype diversity than the eastern and southern populations. Haplotype BR1_05 had the highest frequency on Hokkaido and was found in all three populations (Fig. 2b). Haplotype BR1_06, which was one microsatellite mutational step away from major haplotype BR1_05, was also detected in all three populations. Minor haplotypes BR1_02, BR1_07, and BR1_08, differing from BR1_06 by 1-3 microsatellite mutational steps, were found only in the central population.

Among populations in the southern Kuril Islands close to Hokkaido, one brown bear on Kunashiri Island shared haplotype BR1_04 with Hokkaido bears (Figs. 1 and 2b), and the eastern Hokkaido population had the highest frequency of this haplotype. In contrast, the two haplotypes detected on Etorofu Island were more closely related to haplotypes in continental Eurasia than to those on Hokkaido (Figs. 1 and 2a). Etorofu shared haplotype BR1_12 with the Ural Mountains population, while BR1_13 was restricted to Etorofu Island. On Sakhalin, 


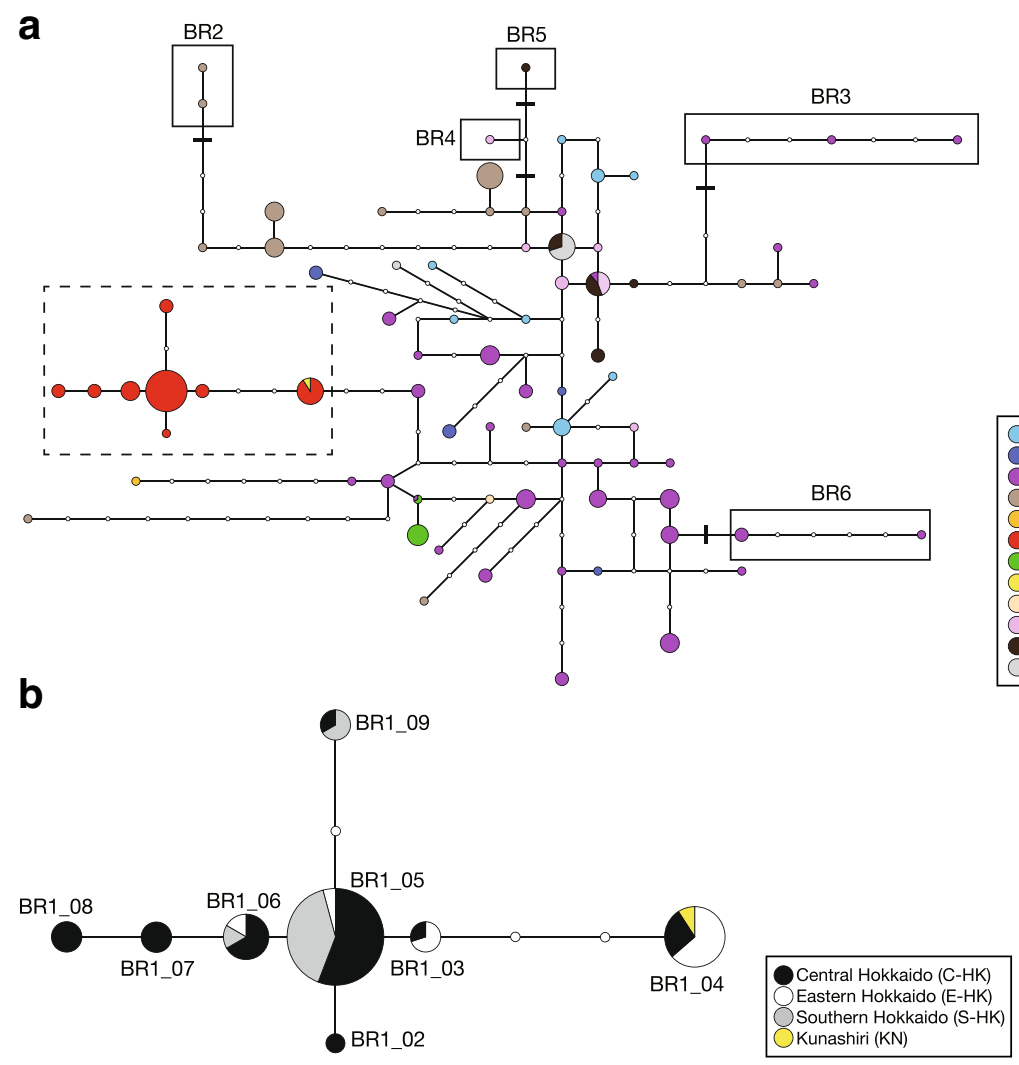

Fig. 2 a Median-joining haplotype network for brown bears, based on Y-chromosomal compound haplotypes combined with Y-linked SNPs from a $3.1 \mathrm{~kb}$ data set and Y-linked microsatellites. Haplotypes enclosed by a dashed line are from Hokkaido (including one Kunashiri brown bear). Haplotypes enclosed by solid lines denote the same haplotypes (BR2-BR6) as those distinguished by only the $3.1 \mathrm{~kb}$ Y-linked data set. The remaining haplotypes have the same haplotype (BR1) distinguished by only the $3.1 \mathrm{~kb}$ data set. Each color represents a different brown bear population. Each black bar crossing a network line denotes a single mutational step revealed by a single nucleotide polymorphism. Small, open circles indicate intermediate haplotypes not actually observed; each line connecting two haplotype circles represents single microsatellite mutational steps. The size of each colored haplotype circle is proportional to the number of individuals having that haplotype. $\mathbf{b}$ MJ network for Hokkaido brown bears (including one from Kunashiri Island), based on the same data as above. Symbols and conventions are as for (a)

haplotype BR1_18 was closely related to haplotypes in continental Eurasia. One Tibetan brown bear had a distinct haplotype (BR1_10) that differed from BR1_11 from the Ural Mountains by six microsatellite mutational steps. Populations in the Ural Mountains and Kamchatka Peninsula had highly variable haplotypes compared with the other populations, but neither population exhibited a clear relationship between genetic relatedness and geographical location.

\section{Differentiation among populations}

Hierarchical analyses by AMOVA were implemented for various geographical partitions of brown bear populations and groups (Table 2, Additional file 2: Tables S2, S3, and S4). Inclusion of the Etorofu population in the Eurasian Continent group resulted in higher among-group variance $(44.43 \%, P<0.001)$ than when it was included in the North American $(41.35 \%, P<0.001)$ or Hokkaido $(23.51 \%$, $P=0.067$ ) groups (Table 2). The Etorofu population is thus more closely related to the continental Eurasian population than with the North American or Hokkaido populations. When the continents (Eurasia and North America) and Hokkaido were partitioned into different groups, the proportion of among-group variance was highest $(54.68 \%, P<$ 0.001 ), and the differentiation was more pronounced. The AMOVA results indicated that the Hokkaido group was highly differentiated from the Eurasian Continent (including Etorofu) and North American groups. There was no genetic connectivity between the Hokkaido group and the continental groups. In addition, there was no substantial population differentiation among the central, eastern, and southern Hokkaido populations.

Although Etorofu Island is geographically close to Kunashiri and Hokkaido islands, it was significantly differentiated from the central, eastern, and southern Hokkaido populations $\left(R_{\mathrm{ST}}=0.92,0.89\right.$, and 0.98 , respectively), but least differentiated from the East Asia population $\left(R_{\mathrm{ST}}=\right.$ 0.18) (Table 3). The three Hokkaido populations were 
Table 2 Analysis of molecular variance (AMOVA) for Y-chromosomal polymorphisms in various geographical partitions

\begin{tabular}{|c|c|c|c|}
\hline Geographical partitions & Sum of squares & Variance components & Percentage of variance (\%) \\
\hline \multicolumn{4}{|l|}{$(E U+E T), N A$, and HK ( $\left.N_{\text {Groups }}=3\right)$} \\
\hline Among groups & 5290.74 & $38.71^{*}$ & 44.43 \\
\hline Among population, within groups & 2729.17 & $17.89^{*}$ & 20.54 \\
\hline Within populations & 6104.21 & $30.52^{*}$ & 35.03 \\
\hline \multicolumn{4}{|l|}{$E U,(N A+E T)$, and HK (N $\left.N_{\text {Groups }}=3\right)$} \\
\hline Among groups & 5212.04 & $34.79^{*}$ & 41.35 \\
\hline Among population, within groups & 2807.87 & $18.81^{*}$ & 22.36 \\
\hline Within populations & 6104.21 & $30.52^{*}$ & 36.28 \\
\hline \multicolumn{4}{|l|}{$E U, N A$, and $(H K+E T)\left(N_{\text {Groups }}=3\right)$} \\
\hline Among groups & 3597.58 & 18.68 & 23.51 \\
\hline Among population, within groups & 4422.33 & $30.24^{*}$ & 38.06 \\
\hline Within populations & 6104.21 & $30.52^{*}$ & 38.42 \\
\hline \multicolumn{4}{|l|}{$[(E U+E T), N A], H K\left(N_{\text {Groups }}=2\right)$} \\
\hline Among groups & 5122.78 & $57.32^{*}$ & 54.68 \\
\hline Among population, within groups & 2897.13 & $16.99^{*}$ & 16.21 \\
\hline Within populations & 6104.21 & $30.52^{*}$ & 29.12 \\
\hline \multicolumn{4}{|l|}{ Within $(H K+E T)\left(N_{\text {Groups }}=1\right)$} \\
\hline Among populations & 2256.75 & $49.72^{*}$ & 82.27 \\
\hline Within populations & 653.90 & 10.72 & 17.73 \\
\hline \multicolumn{4}{|l|}{ Within HK $\left(\mathrm{N}_{\text {Groups }}=1\right)$} \\
\hline Among populations & 235.27 & $6.40^{*}$ & 33.95 \\
\hline Within populations & 647.50 & 12.45 & 66.05 \\
\hline
\end{tabular}

*P<0.001

EU Eurasian Continent (Central Europe, Northern Europe, Western Asia, Eastern Asia), NA North American Continent (Northwest America, ABC Islands, Canada), HK Hokkaido (Central Hokkaido, Eastern Hokkaido, Southern Hokkaido), ET Etorofu Island

significantly differentiated from all three North American and all five Eurasian Continental populations. Among the Hokkaido populations, however, the eastern population was significantly differentiated from the central and southern populations $\left(R_{\mathrm{ST}}=0.42\right.$ and 0.58 , respectively), whereas the latter two were not differentiated from one another $\left(R_{\mathrm{ST}}=0.04\right)$.

Excluding the Etorofu population from the Eurasian Continental group, $R_{\mathrm{ST}}$ values between the North American and Eurasian Continental populations were lower

Table 3 Pairwise population differentiations $\left(R_{S T}\right)$ for $Y$-chromosomal DNA markers among brown bear populations

\begin{tabular}{|c|c|c|c|c|c|c|c|c|c|c|c|}
\hline & NW-A & $A B C$ & CAN & C-EU & $\mathrm{N}-\mathrm{EU}$ & W-AS & E-AS & ET & $\mathrm{C}-\mathrm{HK}$ & $\mathrm{E}-\mathrm{HK}$ & S-HK \\
\hline \multicolumn{11}{|l|}{ NW-A } & \\
\hline$A B C$ & -0.03 & & & & & & & & & & \\
\hline CAN & -0.08 & 0.05 & & & & & & & & & \\
\hline C-EU & -0.004 & 0.11 & -0.06 & & & & & & & & \\
\hline N-EU & $0.37^{*}$ & $0.41^{*}$ & $0.36^{*}$ & $0.26^{*}$ & & & & & & & \\
\hline W-AS & $0.169^{*}$ & $0.25^{*}$ & $0.17^{*}$ & $0.14^{*}$ & $0.22^{*}$ & & & & & & \\
\hline E-AS & $0.19^{*}$ & $0.24^{*}$ & $0.18^{*}$ & $0.23^{*}$ & $0.43^{*}$ & $0.45^{*}$ & & & & & \\
\hline ET & $0.73^{*}$ & $0.79^{*}$ & $0.86^{*}$ & $0.59^{*}$ & $0.85^{*}$ & $0.48^{*}$ & $0.18^{*}$ & & & & \\
\hline C-HK & $0.79^{*}$ & $0.77^{*}$ & $0.81^{*}$ & $0.80^{*}$ & $0.77^{*}$ & $0.72^{*}$ & $0.68^{*}$ & $0.92^{*}$ & & & \\
\hline E-HK & $0.63^{*}$ & $0.59^{*}$ & $0.72^{*}$ & $0.64^{*}$ & $0.67^{*}$ & $0.53^{*}$ & $0.48^{*}$ & $0.89^{*}$ & $0.42^{*}$ & & \\
\hline S-HK & $0.89^{*}$ & $0.87^{*}$ & $0.93^{*}$ & $0.84^{*}$ & $0.86^{*}$ & $0.74^{*}$ & $0.65^{*}$ & $0.98^{*}$ & 0.04 & $0.58^{*}$ & \\
\hline
\end{tabular}


than those between the North American and Hokkaido populations, or between the Eurasian Continental and Hokkaido populations.

\section{Bayesian estimates of divergence times}

BATWING was used to estimate the time to the most recent common ancestor (TMRCA) and effective population size $\left(N_{e}\right)$ for paternal lineages based on Y-linked SNPs in the $3.1 \mathrm{~kb}$ data set and six Y-linked microsatellites (Table 4). The mean TMRCA for all males was 472.7 kyBP (thousands of years before present). That for the Hokkaido and Etorofu populations was $127.8 \mathrm{kyBP}$, slightly older than the splitting time between the Hokkaido brown bears and the other populations. The mean TMRCA of the Hokkaido population was $55.3 \mathrm{kyBP}$ with an effective population size of 1723 (569-4380). The splitting time between the Etorofu brown bears and the other populations was $36.9 \mathrm{kyBP}$, and the TMRCA of the Etorofu brown bears was $4.4 \mathrm{kyBP}$ with an effective population size of 295 (31-1125), which was less than one-fifth the size of the Hokkaido population.

\section{Discussion}

The paternal phylogeographic structure of brown bears across northeastern Asia reconstructed by using Y-chromosomal DNA polymorphisms contrasted with the maternal phylogeographic structure not only in continental Eurasia and North America, but also around Hokkaido and adjacent islands. Sex-biased dispersal by the brown bear could have markedly affected the insular brown bear populations, and differentially affected the evolutionary history in the insular and continental populations. The hypothesis that both male and female brown bears colonized from the Eurasian Continent to Hokkaido multiple times together was supported; however, male-mediated gene flow played a role for homogenizing patrilineal genetic variation and resulted in the geographically indistinct paternal phylogeographic structure of brown bears in Hokkaido.

\section{Paternal phylogeography on Hokkaido Island}

Based on paternal DNA, Hokkaido brown bears were highly differentiated from populations in continental Eurasia and North America, indicating a lack of genetic connectivity with the continental populations (Fig. 2a; Tables 2 and 3). The paternal lineage of the Hokkaido brown bears split off from the continental brown bears an estimated 124.6 kyBP (16.5-645.6 kyBP) (Table 4). In contrast, there was only weak phylogeographic structuring of paternal haplotypes throughout continental Eurasia and North America, probably resulting from malemediated gene flow across continents [34]. The paternal lineages on Hokkaido and the continents may have evolved independently, resulting in different evolutionary histories.

In North America, male-mediated gene flow connects populations on the Alaskan $\mathrm{ABC}$ islands with those on the North American mainland and plays an important role in maintaining high genetic variation in the insular populations [34]. In contrast, there was no direct evidence of male-mediated gene flow across the sea straits between Hokkaido Island and continental Eurasia. Malemediated gene flow from the continent appears to have played little role in the patrilineal genetic variation in the Hokkaido population after the separation of Hokkaido Island by the opening of sea straits following the last glacial maximum (LGM). Instead, substantial genetic drift on Hokkaido Island appears to have contributed to paternal genetic diversity and differentiation between the Hokkaido and continental populations. The influence of male-mediated gene flow on the genetic diversity of island populations thus appears to differ from region to region.

While a network of Y-chromosomal haplotypes identified the Hokkaido population as distinct from populations in other regions, there was little geographic structuring within Hokkaido (Figs. 1 and 2). This is incongruent with the results of mtDNA analyses showing three distinct maternal lineages allopatrically distributed on Hokkaido $[25,28]$. This incongruence suggests that strongly male-biased, long distance dispersal played a significant

Table 4 Time to the most recent common ancestor (TMRCA) in thousands of years before present (kyBP), estimated from Ychromosomal DNA markers by BATWING analysis, scaled using effective population size $\left(\mathrm{N}_{\mathrm{e}}\right)$

\begin{tabular}{llllll}
\hline & TMRCA (mean) & Splitting time (mean) & $95 \%$ Credible interval & $\mathrm{N}_{\mathrm{e}}$ (mean) & $95 \%$ Credible interval \\
\hline All brown bears & 472.7 & - & $186.8-1048.8$ & 31,520 & $16,463-55,764$ \\
HK $-(\mathrm{NA}+\mathrm{EU}+\mathrm{ET})$ & - & 124.6 & $16.5-645.6$ & - & - \\
ET $-(\mathrm{NA}+\mathrm{EU}+\mathrm{HK})$ & - & 36.9 & $1.0-277.6$ & - & - \\
HK + ET & 127.8 & - & $40.3-332.1$ & 2457 & $865-6051$ \\
HK & 55.3 & - & $15.7-153.9$ & 1723 & $569-4380$ \\
ET & 4.4 & - & $0.5-15.8$ & 295 & $31-1125$ \\
\hline
\end{tabular}

EU Eurasian Continent (Central Europe, Northern Europe, Western Asia, Eastern Asia, Sakhalin), NA North American Continent (Northwest America, ABC Islands, Canada), HK Hokkaido (Central Hokkaido, Eastern Hokkaido, Southern Hokkaido), ET Etorofu Island 
role in the genetic makeup of the brown bear population. The paternal genetic diversity was much lower on Hokkaido than in the continental populations in North America and Eurasia, indicating that male-biased dispersal was a stronger factor in homogenizing genetic diversity on the restricted small island than across continents.

The paternal lineage of Hokkaido brown bears showed a much more recent coalescence than the maternal lineages. The TMRCA for the paternal lineage was estimated at 55.3 kyBP (15.7-153.9 kyBP) (Table 4). In contrast, Hirata et al. [25] estimated the TMRCA for mtDNA lineages in the Hokkaido population to be $268 \mathrm{kyBP}$ (109-457 kyBP), nearly five times that of the paternal coalescence. The central, eastern, and southern maternal lineages coalesced approximately $27 \mathrm{kyBP}$ (10-49 kyBP), 42 kyBP (14-80 kyBP), and $36 \mathrm{kyBP}$ (12-67 kyBP), respectively, and were more similar to the coalescence time for paternal lineage. Polygyny among brown bears may have led the small male effective population size and caused the much more recent coalescence of paternal lineages. In addition, the difference in TMRCA between the maternal and paternal lineages can be explained by the pronounced sexual bias in brown bear dispersal behavior. Since the brown bear population on Hokkaido formed through the immigration of three different lineages from continental Eurasia in different periods [25], one might expect also to find highly diverged paternal haplotypes descended from the three past pulses of immigration into Hokkaido. Contrary to this expectation, the Y-chromosomal DNA haplotypes detected on Hokkaido were more recently diverged, differing by only a few mutational steps in microsatellites (Figs. 1 and 2; Additional file 2: Table S1). In the $3.1 \mathrm{~kb}$ and $5.3 \mathrm{~kb}$ data sets, all individuals from Hokkaido shared haplotypes BR1 and BR1.4, respectively. No relatively old haplotypes discriminated by more slowly evolving SNPs were found, although these might have been expected considering multiple past pulses of immigration from continental Eurasia. Highly diverged patrilineal lineages previously immigrated into Hokkaido were overridden by more recent immigrant lineage and relatively old haplotypes must have become extinct on Hokkaido. Thus, all paternal haplotypes shared by the Hokkaido brown bears are specific to Hokkaido Island.

We detected one major haplotype (BR1_05) throughout Hokkaido Island (Figs. 1 and 2b; Additional file 2: Table S1). As mentioned in Results, three male individuals (ID 602, 6071, and 6081) had maternal haplotypes that were inconsistent with population region where they were collected, as defined by mtDNA (Fig. 1). These males were probably individuals that had dispersed from their natal area during a single generation. Other studies $[53,54]$ using a combination of mtDNA and autosomal microsatellite markers have also demonstrated dispersal of extant males as well as male-mediated gene flow between natal areas defined by mtDNA lineages (the southern Akan-Shiranuka region, central and eastern Hokkaido). These signs of male-mediated gene flow among populations reiterate that the distinct maternal phylogeographic structure on Hokkaido Island has been maintained by strong female philopatric behavior, despite fairly common male immigration between maternal populations.

Although paternal population structuring was weak, differential and biased pairwise population differentiation was evident among the three Hokkaido populations (Table 3), suggesting a tendency toward biased dispersal and mixing of males from past to present. There was no paternal population differentiation between the central and southern Hokkaido populations, which indicates that frequent movement of males between these populations caused interchange of paternal haplotypes. On the other hand, significant population differentiation between eastern Hokkaido and each of the other two regions suggests some restriction of brown bear migration between these populations. Morphometric data also suggest some differentiation of males between geographical populations defined by mtDNA markers. Although female cranial characters were markedly differentiated among the populations, males were similar between the central and southern Hokkaido populations, whereas males in eastern Hokkaido were distinct [55]. The Shiretoko Peninsula in eastern Hokkaido has highest density of the brown bears on Hokkaido Island. The high bear density may have induced these males to exhibit more sedentary behavior than in other areas and restricted male-mediated gene flow into this area.

\section{Paternal phylogeography in the southern Kuril Islands}

The maternal lineage in the southern Kuril Islands (Kunashiri and Etorofu) apparently originated from eastern Hokkaido [25]. Contrary to expectations based on mtDNA analyses that the paternal lineage on Etorofu would have the same demographic history as that on Kunashiri, we detected lineage differentiation between Hokkaido/Kunashiri and Etorofu. The two haplotypes detected on Etorofu were more closely related to haplotypes from continental Eurasia than to those from Hokkaido, even though a large sample $(n=55)$ from across Hokkaido was genotyped (Fig. 2a; Tables 2 and 3). The TMRCA for the Hokkaido + Etorofu male populations (127.8 kyBP) was older than for the matrilineal lineage and was roughly contemporaneous with the split of the Hokkaido lineage from the continental lineages (124.6 kyBP) (Table 4). In the maternal lineage, brown bears from both southern Kuril Islands were estimated to have diverged from the eastern Hokkaido lineage less than $42 \mathrm{kyBP}(14-80 \mathrm{kyBP})$ [25]. The estimated 
male effective population size on Etorofu Island was much smaller than that on Hokkaido Island. A small number of individuals may have contributed to the makeup of the population on Etorofu.

Y-chromosomal DNA was genotyped for ten individuals from Etorofu, of which four had been included in an analysis of complete mtDNA sequences [25]; three of the four individuals were identical in mtDNA haplotype, excluding the fast-evolving variable-number tandem repeats in the control region. Most brown bears on Etorofu likely belong to the same maternal lineage. Only two Y-chromosomal DNA haplotypes differing by one microsatellite mutational step were found among 10 individuals from Etorofu Island, giving the lowest genetic diversity of among populations (Fig. 2a; Table 1). Etorofu Island brown bears also likely comprise the paternally related lineage. Geologically, Kunashiri Island was connected to Hokkaido by a land bridge 8-110 kyBP, whereas Etorofu Island remained separate during that period [56]. The brown bear population on Etorofu may have been maintained by inbreeding for a long time, with a founder event and subsequent genetic drift leading to the low diversity we observed. In contrast to the maternal lineages, the present-day paternal lineage on Etorofu possibly originated by the dispersal of male individuals from continental Eurasia. Thus, the different dispersal behaviors of male and female brown bears appear to have contributed to the makeup of the Etorofu population, in which maternal and paternal lineages had different origins. Furthermore, there appears to have been little recent male-mediated gene flow between Hokkaido/ Kunashiri and Etorofu.

\section{Paternal phylogeography on the Eurasian continent}

Brown bear populations in the Ural Mountains and Kamchatka Peninsula had higher haplotype variation than other populations, but neither population showed a clear relationship between genetic relatedness and geographical location. Western Asia, including the Ural Mountains, had the highest index values for paternal genetic diversity in our study (Table 1), whereas only one mtDNA lineage (clade 3a1) has been detected in the same region, with relatively low maternal genetic diversity [25, 26, 29-31]. High paternal genetic variation within populations in this region, compared to low genetic differentiation among the populations, supports the conclusion that male-mediated gene flow contributed highly to the brown bear population history in continental Eurasia, especially around the Ural Mountains.

\section{Conclusions}

Brown bears on Hokkaido and the adjacent southern Kuril Islands experienced different maternal and paternal evolutionary histories, demonstrating that the phylogeography in this region is considerably more complicated than would be expected from mtDNA studies alone. The weak spatial structuring of paternal lineages detected on Hokkaido appears to have resulted from extensive, continual gene flow via male dispersal among natal populations after the last population immigrated into Hokkaido from eastern Siberia via a land bridge during the last glacial period. The paternal genetic structure did not show distinct allopatric lineages, as have been observed for maternal (mtDNA) markers. While there were indications of heterogeneous male-mediated gene flow among populations on Hokkaido, it is unclear how much this influenced the connectivity and the maintenance of the local populations. Our results indicate that sex-biased dispersal has played a significant role in the evolutionary history of the brown bear in continental populations and in peripheral insular populations such as on Hokkaido, the southern Kuril Islands, and Sakhalin. Biparentally inherited autosomal DNA and whole-genomic data could further clarify the detailed demographic history and local adaptation of Asian brown bears.

\section{Additional files}

\begin{abstract}
Additional file 1: Figure S1. Median-joining haplotype network for brown, polar, and American black bears, based on the $3.1 \mathrm{~kb}$ Y-linked data set. Figure S2. Median-joining haplotype network for brown, polar, and American black bears, based on the $5.3 \mathrm{~kb}$ Y-linked data set. Figure S3. Median-joining haplotype network for brown bears, based on $Y$ chromosomal compound haplotypes combined with Y-linked SNPs from a $3.1 \mathrm{~kb}$ data set and Y-linked microsatellites. Haplotypes enclosed by a dashed line are from Hokkaido (including one Kunashiri brown bear). Figure S4. Map of Eurasia showing the geographical distribution of brown bear Y-chromosomal compound haplotypes. Each symbol represents one individual. Figure S5. Enlargement of the larger boxed area in Fig. S4, show ing the geographical distribution of brown bear Y-chromosomal compound haplotypes around the Ural Mountains. (ZIP $4.95 \mathrm{mb}$ )

Additional file 2:Table S1. List of Y-chromosomal DNA compound haplotypes (YDNA haplotype), Y-chromosomal haplotypes based on only the $3.1 \mathrm{~kb}$ data set (YSNP_haplotype), Y-linked SNPs in the $3.1 \mathrm{~kb}$ data set, fragment sizes of six $Y$-linked microsatellites markers, and the number of individuals from each geographical regions having each $Y$ chromosomal DNA compound haplotypes. Table S2. Analysis of molecular variance (AMOVA) for brown bear Y-chromosomal polymorphisms in various geographical partitions. Table S3. Analysis of molecular variance (AMOVA) for brown bear Y-chromosomal polymorphisms in various geographical partitions. Table S4. Analysis of molecular variance (AMOVA) for brown bear Y-chromosomal polymorphisms in various geographical partitions. (ZIP 63 kb)
\end{abstract}

\section{Acknowledgements}

We thank Kobe Municipal Oji Zoo, M. A. Meshcheryakov, S. A. Piskunov, and S. I. Malygin for providing specimens, and staff members of the museum of Institute of Plant and Animal Ecology (Yekaterinburg) for their help, and Prof. Matthew Dick for commenting on and editing the manuscript.

\section{Funding}

This work was supported in part by a Grant-in-Aid for Scientific Research (grant number 15H04410) from the Japan Society of the Promotion of Science (JSPS), a Grant-in-Aid for JSPS Fellows (research project number 14 J02026), a Joint Research Project Grant from JSPS and the Russian Foundation for Basic Research (RFBR, grant numbers 16-54-50,004 and 15-04-03882), and a Grant from the Joint Research Program of the Japan Arctic Research Network Center. 


\section{Availability of data and materials}

The Y-chromosomal DNA sequences we obtained have been deposited in the DDBJ/NCBI/EMBL databases under accession numbers LC203037-LC203044.

\section{Authors' contributions}

$\mathrm{DH}$ and RM designed the study. TM, AVA, GFB, PAK, and KM collected samples. DH performed experiments and analyzed the data. DH and RM interpreted the results and wrote the manuscript. All authors read and approved the final manuscript.

\section{Ethics approval and consent to participate}

Not applicable.

\section{Consent for publication}

Not applicable.

\section{Competing interests}

The authors declare that they have no competing interests.

\section{Publisher's Note}

Springer Nature remains neutral with regard to jurisdictional claims in published maps and institutional affiliations.

\section{Author details}

'Department of Biological Sciences, Faculty of Science, Hokkaido University, Sapporo 060-0810, Japan. ${ }^{2}$ Institute of Environmental Sciences, Hokkaido Research Organization, Sapporo 080-0819, Japan. ${ }^{3}$ Zoological Institute, Russian Academy of Sciences, St. Petersburg 199034, Russia. Institute of Plant and Animal Ecology, Russian Academy of Sciences, Ekaterinburg 620219, Russia. ${ }^{5}$ College of Bioresource Sciences, Nihon University, Fujisawa 252-0880, Japan

Received: 28 June 2017 Accepted: 15 November 2017

Published online: 30 November 2017

\section{References}

1. Petit E, Balloux F, Excoffier L. Mammalian population genetics: why not Y? Trends Ecol Evol. 2002:17:28-33.

2. Prugnolle F, de Meeus T. Inferring sex-biased dispersal from population genetic tools: a review. Heredity. 2002;88:161-5.

3. Lawson Handley $\amalg$, Perrin N. Advances in our understanding of mammalian sex-biased dispersal. Mol Ecol. 2007;16:1559-78.

4. Greenwood PJ. Mating systems, philopatry and dispersal in birds and mammals. Anim Behav. 1980;28:1140-62.

5. Dobson FS. Competition for mates and predominant juvenile male dispersal in mammals. Anim Behav. 1982;30:1183-92.

6. Pusey AE. Sex-biased dispersal and inbreeding avoidance in birds and mammals. Trends Ecol Evol. 1987;2:295-9.

7. Hughes JF, Rozen S. Genomics and genetics of human and primate $Y$ chromosomes. Annu Rev Genomics Hum Genet. 2012;13:83-108.

8. Wei W, Ayub Q, Xue Y, Tyler-Smith CA. Comparison of Y-chromosomal lineage dating using either resequencing or Y-SNP plus Y-STR genotyping. Forensic Sci Int Genet. 2013;7:568-72.

9. Eriksson J, Siedel H, Lukas D, Kayser M, Erler A, Hashimoto C, et al. Ychromosome analysis confirms highly sex-biased dispersal and suggests a low male effective population size in bonobos (Pan paniscus). Mol Ecol. 2006;15:939-49.

10. Langergraber KE, Siedel H, Mitani JC, Wrangham RW, Reynolds V, Hunt K, et al. The genetic signature of sex-biased migration in patrilocal chimpanzees and humans. PLoS One. 2007;2:e973.

11. Nater A, Nietlisbach P, Arora N, Van Schaik CP, Van Noordwijk MA, Willems $E P$, et al. Sex-biased dispersal and volcanic activities shaped phylogeographic patterns of extant orangutans (genus: Pongo). Mol Biol Evol. 2011;28:2275-88.

12. Nietlisbach P, Arora N, Nater A, Goossens B, Van Schaik CP, Krützen M. Heavily male-biased long-distance dispersal of orang-utans (genus: Pongo), as revealed by Y-chromosomal and mitochondrial genetic markers. Mol Ecol. 2012;21:3173-86.

13. Hammond RL, Lawson Handley LJ, Winney BJ, Bruford MW, Perrin N. Genetic evidence for female-biased dispersal and gene flow in a polygynous primate. Proc R Soc B Biol Sci. 2006;273:479-84.
14. Brown SK, Pedersen NC, Jafarishorijeh S, Bannasch DL, Ahrens KD, Te WJ, et al. Phylogenetic distinctiveness of middle eastern and southeast Asian village dog Y chromosomes illuminates dog origins. PLoS One. 2011;6:e28496.

15. Sacks BN, Brown SK, Stephens D, Pedersen NC, Te WJ, Berry OY. Chromosome analysis of dingoes and southeast asian village dogs suggests a neolithic continental expansion from southeast asia followed by multiple austronesian dispersals. Mol Biol Evol. 2013;30:1103-18.

16. Meadows JRS, Hanotte O, Drögemüller C, Calvo J, Godfrey R, Coltman D, et al. Globally dispersed Y chromosomal haplotypes in wild and domestic sheep. Anim Genet. 2006;37:444-53.

17. Lippold S, Knapp M, Kuznetsova T, Leonard JA, Benecke N, Ludwig A, et al. Discovery of lost diversity of paternal horse lineages using ancient DNA. Nat Commun. 2011:2:450.

18. McLellan BN, Hovey FW. Natal dispersal of grizzly bears. Can J Zool. 2001;79: 838-44.

19. Proctor MF, McLellan BN, Strobeck C, Barclay RMR. Gender-specific dispersal distances of grizzly bears estimated by genetic analysis. Can J Zool. 2004:82:1108-18.

20. Støen OG, Zedrosser A, Saebø S, Swenson JE. Inversely density-dependent natal dispersal in brown bears Ursus Arctos. Oecologia. 2006;148:356-64.

21. Zedrosser A, Støen OG, Sæbø S, Swenson JE. Should I stay or should I go? Natal dispersal in the brown bear. Anim Behav. 2007;74:369-76.

22. Nakagome S, Pecon-Slattery J, Masuda R. Unequal rates of $Y$ chromosome gene divergence during speciation of the family Ursidae. Mol Biol Evol. 2008;25:1344-56.

23. Davison J, Ho SYW, Bray SC, Korsten M, Tammeleht E, Hindrikson M, et al. Late-quaternary biogeographic scenarios for the brown bear (Ursus arctos), a wild mammal model species. Quat Sci Rev. 2011;30:418-30.

24. Gus'kov W, Sheremet'eva IN, Seredkin IV, Kryukov AP. Mitochondrial cytochrome $b$ gene variation in brown bear (Ursus arctos Linnaeus, 1758) from southern part of Russian far east. Russ. J. Genet. 2013;49:1213-8.

25. Hirata D, Mano T, Abramov AV, Baryshnikov GF, Kosintsev PA, Vorobiev AA, et al. Molecular phylogeography of the brown bear (Ursus arctos) in northeastern Asia based on analyses of complete mitochondrial DNA sequences. Mol Biol Evol. 2013;30:1644-52.

26. Hirata D, Abramov AV, Baryshnikov GF, Masuda R. Mitochondrial DNA haplogrouping of the brown bear, Ursus arctos (Carnivora: Ursidae) in Asia, based on a newly developed APLP analysis. Biol. J. Linn. Soc. 2014;111:627-35.

27. Keis M, Remm J, Ho SYW, Davison J, Tammeleht E, Tumanov IL, et al. Complete mitochondrial genomes and a novel spatial genetic method reveal cryptic phylogeographical structure and migration patterns among brown bears in north-western Eurasia. J Biogeogr. 2013;40:915-27.

28. Matsuhashi T, Masuda R, Mano T, Yoshida MC. Microevolution of the mitochondrial DNA control region in the Japanese brown bear (Ursus arctos) population. Mol Biol Evol. 1999;16:676-84.

29. Saarma U, Ho SYW, Pybus OG, Kaljuste M, Tumanov IL, Kojola I, et al. Mitogenetic structure of brown bears (Ursus arctos L.) in northeastern Europe and a new time frame for the formation of European brown bear lineages. Mol Ecol. 2007;16:401-13.

30. Korsten M, Ho SYW, Davison J, Pähn B, Vulla E, Roht M, et al. Sudden expansion of a single brown bear maternal lineage across northern continental Eurasia after the last ice age: a general demographic model for mammals? Mol Ecol. 2009:18:1963-79.

31. Murtskhvaladze M, Gavashelishvili A, Tarkhnishvili D. Geographic and genetic boundaries of brown bear (Ursus arctos) population in the Caucasus. Mol Ecol. 2010;19:1829-41.

32. Kutschera VE, Bidon T, Hailer F, Rodi JL, Fain SR, Janke A. Bears in a forest of gene trees: phylogenetic inference is complicated by incomplete lineage sorting and gene flow. Mol Biol Evol. 2014;31:2004-17.

33. Kutschera VE, Frosch C, Janke A, Skírnisson K, Bidon T, Lecomte N, et al. High genetic variability of vagrant polar bears illustrates importance of population connectivity in fragmented sea ice habitats. Anim Conserv. 2016;19:337-49

34. Bidon $T$, Janke A, Fain SR, Eiken HG, Hagen SB, Saarma U, et al. Brown and polar bear $Y$ chromosomes reveal extensive male-biased gene flow within brother lineages. Mol Biol Evol. 2014;31:1353-63.

35. Bidon T, Schreck N, Hailer F, Nilsson MA, Janke A. Genome-wide search identifies $1.9 \mathrm{Mb}$ from the polar bear $\mathrm{Y}$ chromosome for evolutionary analyses. Genome Biol Evol. 2015;7:2010-22.

36. Schregel J, Eiken HG, Grøndahl FA, Hailer F, Aspi J , Kojola l, et al. Y chromosome haplotype distribution of brown bears (Ursus arctos) in 
northern Europe provides insight into population history and recovery. Mol Ecol. 2015;24:6041-60.

37. Bidon T, Frosch C, Eiken HG, Kutschera VE, Hagen SB, Aarnes SG, et al. A sensitive and specific multiplex PCR approach for sex identification of ursine and tremarctine bears suitable for non-invasive samples. Mol Ecol Resour. 2013;13:362-8.

38. Ewing B, Hillier L, Wendl MC, Green P. Base-calling of automated sequencer traces usingPhred. I. Accuracy assessment. Genome Res. 1998;8:175-85.

39. Ewing B, Green P. Base-calling of automated sequencer traces using phred. II. Error probabilities. Genome Res. 1998;8:186-94.

40. Maddison WP, Maddison DR. Mesquite: a modular system for evolutionary analysis. Version 2.75. 2011. http.//mesquiteproject.org. Accessed 8 August 2017.

41. Edgar RC. MUSCLE: Multiple sequence alignment with high accuracy and high throughput. Nucleic Acids Res. 2004;32:1792-7.

42. Kumar S, Stecher G, Tamura K. MEGA7: Molecular Evolutionary Genetics Analysis Version 7.0 for Bigger Datasets. Mol Biol Evol. 2016;33:1870-4.

43. Librado P, Rozas J. DnaSP v5: a software for comprehensive analysis of DNA polymorphism data. Bioinformatics. 2009;25:1451-2.

44. Excoffier $L$, Lischer HEL. Arlequin suite ver 3.5: a new series of programs to perform population genetics analyses under Linux and windows. Mol Ecol Resour. 2010;10:564-7.

45. Garza JC, Williamson EG. Detection of reduction in population size using data from microsatellite loci. Mol Ecol. 2001;10:305-18.

46. Bandelt HJ, Forster P, Röhl A. Median-joining networks for inferring intraspecific phylogenies. Mol Biol Evol. 1999;16:37-48.

47. Leigh JW, Bryant D. Popart: full-feature software for haplotype network construction. Methods Ecol Evol. 2015;6:1110-6.

48. Slatkin MA. Measure of population subdivision based on microsatellite allele frequencies. Genetics. 1995;139:457-62.

49. Wilson IJ, Weale ME, Balding DJ. Inferences from DNA data: population histories, evolutionary processes and forensic match probabilities. J R Stat Soc Ser A. 2003;166:155-88.

50. Zhivotovsky LA, Underhill PA, Cinnioğlu C, Kayser M, Morar B, Kivisild T, et al. The effective mutation rate at $Y$ chromosome short tandem repeats, with application to human population-divergence time. Am J Hum Genet. 2004;74:50-61.

51. Rambaut, A., Suchard, M., Xie, D., \& Drummond, A. Tracer v1. 6. 2014. http://tree.bio.ed.ac.uk/software/tracer/. Accessed 8 August 2017.

52. Cahill JA, Green RE, Fulton TL, Stiller M, Jay F, Ovsyanikov N, et al. Genomic evidence for island population conversion resolves conflicting theories of polar bear evolution. PLoS Genet. 2013;9:e1003345.

53. Sato Y, Itoh T, Mori Y, Satoh Y, Mano T. Dispersal of male bears into peripheral habitats inferred from mtDNA haplotypes. Ursus. 2011;22:120-32.

54. Itoh T, Sato Y, Kobayashi K, Mano T, Iwata R. Effective dispersal of brown bears (Ursus arctos) in eastern Hokkaido, inferred from analyses of mitochondrial DNA and microsatellites. Mammal Study. 2012;37:29-41.

55. Baryshnikov GF, Mano T, Masuda R. Taxonomic differentiation of Ursus Arctos (Carnivora, Ursidae) from south Okhotsk Sea islands on the basis of morphometrical analysis of skull and teeth. Russ J Theriol. 2004;3:77-88.

56. Igarashi Y. Geohistorical and paleoecological significance of south Kuril Islands; especially on connection with Hokkaido Island. Wildl. Forum 2000;6:p. 11-21 (in Japanese).

\section{Submit your next manuscript to BioMed Central and we will help you at every step:}

- We accept pre-submission inquiries

- Our selector tool helps you to find the most relevant journal

- We provide round the clock customer support

- Convenient online submission

- Thorough peer review

- Inclusion in PubMed and all major indexing services

- Maximum visibility for your research

Submit your manuscript at www.biomedcentral.com/submit

) Biomed Central 